\title{
Transient Effect of Aircraft Propeller Blade by using Composites
}

\author{
${ }^{1}$ Kappa Shiv Kumar \\ M.Tech. Student, \\ Dept. of Mechanical Engineering \\ Raghu Engineering College (A), \\ Bheemunipatnam, Vishakapatnam, \\ Andhra Pradesh, pin code 531162, India
}

\author{
2,*Amit Kumar Mehar \\ Associate Professor, \\ Dept. of Mechanical Engineering, \\ Raghu Engineering College (A), \\ Bheemunipatnam, Vishakapatnam, \\ Andhra Pradesh, pin code 531162, India
}

\begin{abstract}
A propeller is a type of fan that transmits power by converting rotational motion into thrust. A pressure difference is produced between the forward and rear surfaces of the airfoil-shaped blade, and a fluid (such as air) is accelerated behind the blade. Propeller dynamics can be modeled by both Bernoulli's principle and Newton's third law. Aircraft propeller is sometimes colloquially known as an air screw propeller

The present work is directed towards the study of composite aircraft propeller working and its terminology, simulation and flow simulation of composite aircraft propeller has been performed. To analyze the composite aircraft propeller in ANSYS software.

Static and dynamic analysis is to determine the deformation, stress and strain of the composite aircraft propeller blade. Fatigue analysis to estimate the life of the component.

The optimizing the propeller blades varying the no of blades 2,3\&5 blades and also optimizing the material E-glass Epoxy, Aluminum Alloy and Carbon Epoxy. 3D modeling done in CATIA parametric software. Aircraft
\end{abstract}

An aircraft is a machine that is able to fly by gaining support from the air. It counters the force of gravity by using either static lift or by using the dynamic lift of an airfoil, or in a few cases the downward thrust from engines. Common examples of aircraft include airplanes, helicopters, airships (including blimps), glid ers, parameters and hot air.

The human activity that surrounds aircraft is called aviation. The science of aviation, including designing and building aircraft, is called aeronautics. Crewed aircraft are flown by an onboard pilot, but unmanned aerial vehicles may be remotely controlled or self-controlled by onboard computers. Aircraft may be classified by different criteria, such as lift type, aircraft propulsion, usage and others.

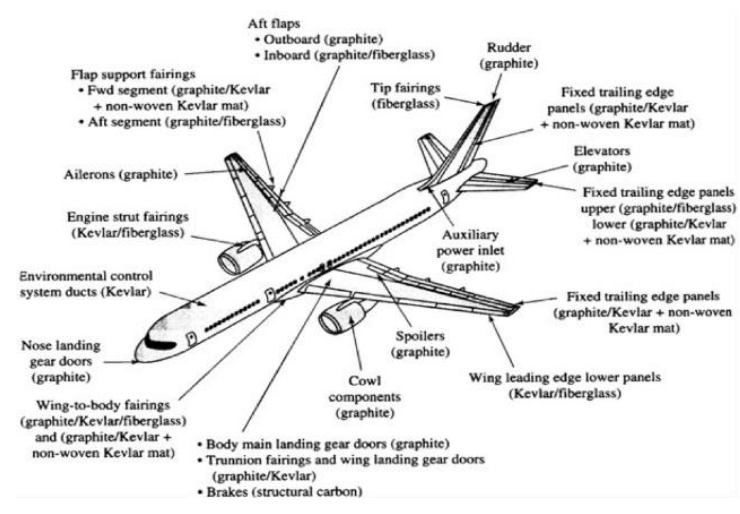

Figure 1.1 aircraft

\section{Propeller aircraft}

Propeller aircraft use one or more propellers (airscrews) to create thrust in a forward direction. The propeller is usually mounted in front of the power source in tractor configuration but can be mounted behind in pusher configuration. Variations of propeller layout include contra-rotating propellers and ducted fans.

\section{Propeller blade}

Thrust is the force that moves the aircraft through the air. Thrust is generated by the propulsion system of the aircraft. There are different types of propulsion systems develop thrust in different ways, although it usually generated through some application of Newton's Third Law. Propeller is one of the propulsion systems. The purpose of the propeller is to move the aircraft through the air. The propeller consists of two or more blades connected together by a hub. The hub serves to attach the blades to the engine shaft. .

\section{Propeller blade}

Thrust is the force that moves the aircraft through the air. Thrust is generated by the propulsion system of the aircraft. There are different types of propulsion systems develop thrust in different ways, although it usually generated through some application of Newton's Third Law. Propeller is one of the propulsion systems. The purpose of the propeller is to move the aircraft through the air. The propeller consists of two or more blades connected together by a hub. The hub serves to attach the blades to the engine shaft. .

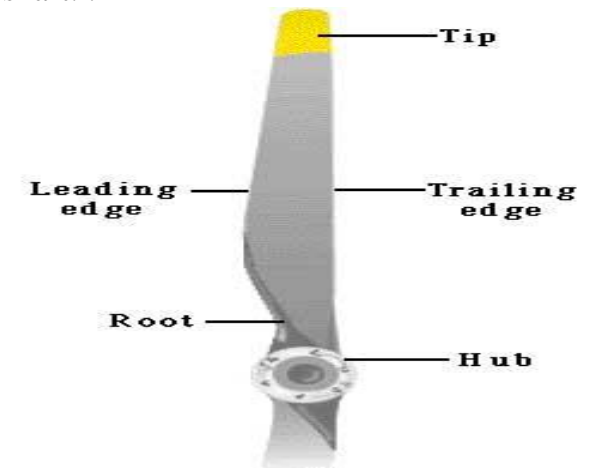

Blade Face is the surface of the propeller blade that corresponds to the lower surface of an airfoil or flat side, we called Blade Face. 


\section{LITERATURE REVIEW}

Y.S Rao and B.S.Reddy [1] shows composite propeller blades are safe in case of resonance phenomena in their harmonic analysis. Vibration defect can also be controlled in case of composite as damping effect is more. They had done a comparison of harmonic analysis using ansys software between aluminium metal and S2 Glass fabric/Epoxy. From their result maximum displacement in case of composite is 0.08192 which very less than aluminium propeller blade 0.1784 .

M.A.Khan et al[2] observed inter laminar shear stress for composite material considering different no of layer and shows there is strong bonding between the layers. Eigan value analysis shows composite material has $80.5 \%$ more natural frequency than aluminium propeller. In their static analysis they had shown composite consist of separate layer.

V Ganesh et al. [3] had done static and modal analysis for aluminium propeller and composite (carbon reinforced plastics) propeller. From their analysis it shows blade deflection in case composite propeller is very less compare to aluminium. Besides that they also observed the stress strain variation for the strength analysis.

\section{INTRODUCTION TO CAD}

Computer-aided design (CAD) is the use of computer systems (or workstations) to aid in the creation, modification, analysis, or optimization of a design. CAD software is used to increase the productivity of the designer, improve the quality of design, improve communications through documentation, and to create a database for manufacturing. CAD output is often in the form of electronic files for print, machining, or other manufacturing operations. The term CADD (for Computer Aided Design and Drafting) is also used.

\section{INTRODUCTION TO CATIA}

CATIA is an acronym for Computer Aided Threedimensional Interactive Application. It is one of the leading 3D software used by organizations in multiple industries ranging from aerospace, automobile to consumer products.

CATIA is a multi platform 3D software suite developed by Dassault Systèmes, encompassing CAD, CAM as well as CAE. Dassault is a French engineering giant active in the field of aviation, 3D design, 3D digital mock-ups, and product lifecycle management (PLM) software. CATIA is a solid modelling tool that unites the 3D parametric features with 2D tools and also addresses every design-tomanufacturing process. In addition to creating solid models and assemblies, CATIA also provides generating orthographic, section, auxiliary, isometric or detailed 2D drawing views. It is also possible to generate model dimensions and create reference dimensions in the drawing views. The bi-directionally associative property of CATIA ensures that the modifications made in the model are reflected in the drawing views and vice-versa.

\author{
General characteristics \\ - Crew: None \\ - Capacity: $68 \mathrm{~kg}(150 \mathrm{lb})$ payload \\ - $\quad$ Length: $5.85 \mathrm{~m}$ (19 ft 2 in) \\ - Wingspan: $8.54 \mathrm{~m}$ (28 ft 0 in) \\ - Height: $1.25 \mathrm{~m}$ (4 ft $1 \mathrm{in})$ \\ - $\quad$ Gross weight: $500 \mathrm{~kg}(1,100 \mathrm{lb})$ \\ - $\quad$ Airfoil: NACA 64 A 008 \\ - $\quad$ Powerplant: $1 \times$ Limbach L 550, $40 \mathrm{~kW}(47 \mathrm{hp})$
}

\section{Performance}

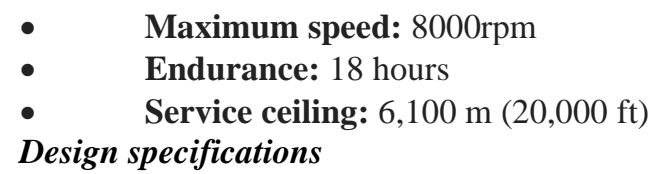

\section{Design specifications}

\begin{tabular}{cc|}
\hline S.No & Parameters \\
\hline 1 & 2bladed propeller \\
2 & Radius of hub $=50 \mathrm{~mm}$ \\
3 & Radius of Propeller $=500 \mathrm{~mm}$ \\
4 & Power $=40 \mathrm{kw}$ \\
5 & Rpm $=8000$ \\
\hline
\end{tabular}

CASE1: aircraft propeller with 2 blades

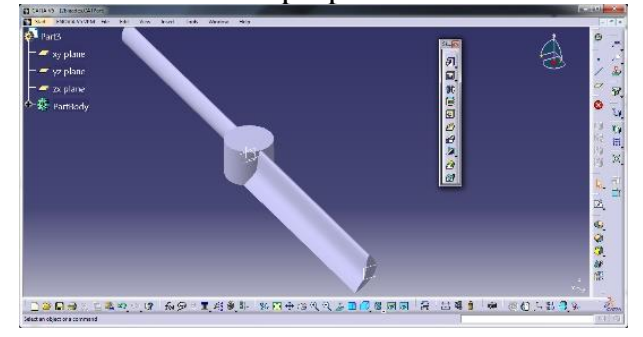

CASE2: aircraft propeller with 3 blades

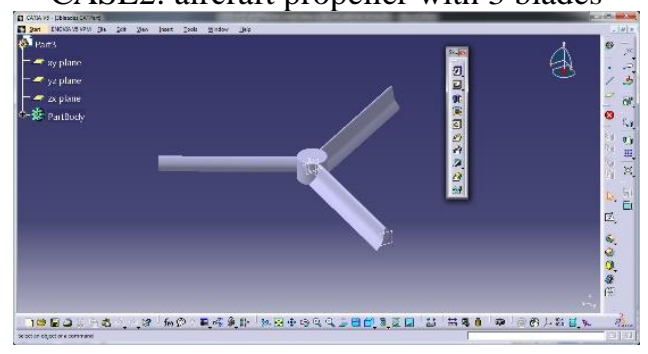

CASE3: aircraft propeller with 5 blades

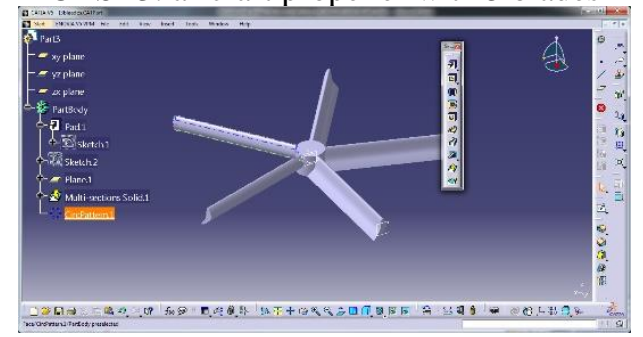

INTRODUCTION TO FEA

Finite element analysis is a method of solving, usually approximately, certain problems in engineering and 
science. It is used mainly for problems for which no exact solution, expressible in some mathematical form, is available. As such, it is a numerical rather than an analytical method. Methods of this type are needed because analytical methods cannot cope with the real, complicated problems that are met with in engineering. For example, engineering strength of materials or the mathematical theory of elasticity can be used to calculate analytically the stresses and strains in a bent beam, but neither will be very successful in finding out what is happening in part of a car suspension system during cornering.

Structural Analysis

ANSYS Autodyn is computer simulation tool for simulating the response of materials to short duration severe loadings from impact, high pressure or explosions.

ANSYS Mechanical

ANSYS Mechanical is a finite element analysis tool for structural analysis, including linear, nonlinear and dynamic studies. This computer simulation product provides finite elements to model behavior, and supports material models and equation solvers for a wide range of mechanical design problems. ANSYS Mechanical also includes thermal analysis and coupled-physics capabilities involving acoustics, piezoelectric, thermal-structural and thermo-electric analysis.

\section{STATIC ANALYSIS OF AIRCRAFT PROPELLER BLADE}

Aluminum alloy

\begin{tabular}{|c|c|c|c|c|}
\hline A & B & & c & D \\
\hline Property & Value & & Unit & 8 \\
\hline Density & 4620 & $\mathrm{~kg}^{\wedge}-3$ & & \pm 0 \\
\hline \pm Isotropic Secant Coefficient of Thermal Expansion & & & & 回 \\
\hline Z Isotopic Elastioty & & & & 回 \\
\hline Derive from & Young's Mod... • & & & \\
\hline Young's Modulus & $9.6 E+10$ & 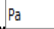 & & \pm \\
\hline Poisson's Ratio & 0.36 & & & \\
\hline
\end{tabular}

Carbon epoxy

\begin{tabular}{|c|c|c|c|}
\hline Property & Value & & Unit \\
\hline Z Density & 1800 & $\mathrm{kgm}^{\wedge}-3$ & $\dot{1}$ \\
\hline \multicolumn{4}{|l|}{ Q 8 isotopocicEssicty } \\
\hline Derive from & Youngs'sodu... & & \\
\hline Young's Modulus & $4.55+100$ & Pa & 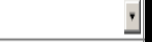 \\
\hline Possons'Ratio & 0.35 & & \\
\hline
\end{tabular}

E-glass epoxy

\begin{tabular}{|c|c|c|c|}
\hline Property & Value & \multicolumn{2}{|c|}{ Unit } \\
\hline 7 Density & 2770 & $\mathrm{kgm}^{\wedge} \cdot 3$ & - \\
\hline$\square$ Isotropic Elasticty & & & \\
\hline Derive from & Young's Modu... '. & & \\
\hline Young's Moddus & 7.1E+10 & $\mathrm{Pa}$ & 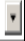 \\
\hline Poisson's Ratio & 0,33 & & \\
\hline
\end{tabular}

Case1: Aircraft propeller with 2 blades Imported model

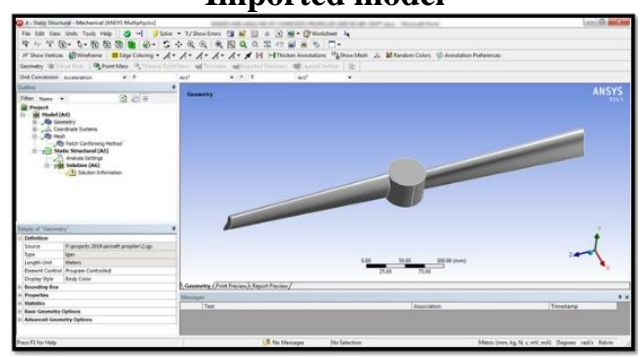

Meshed model

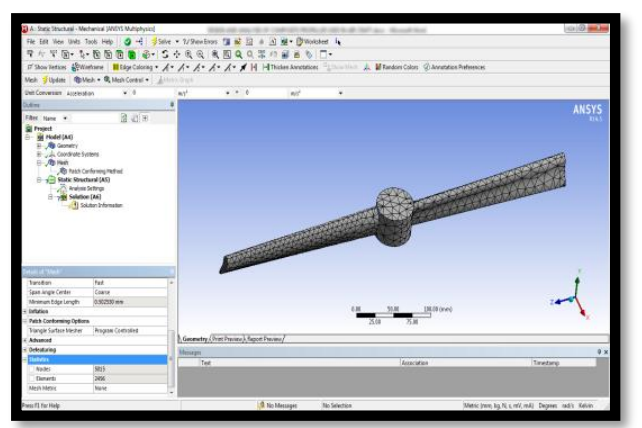

Boundary conditions

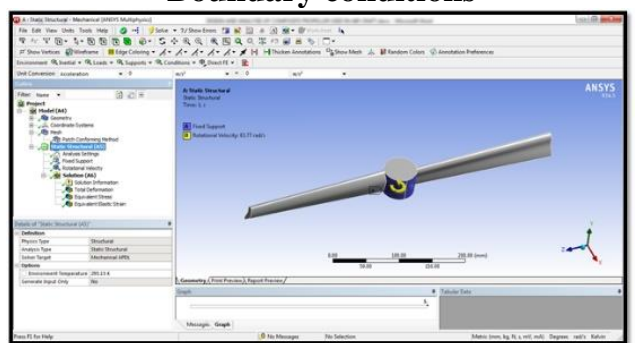

Material- carbon epoxy Deformation
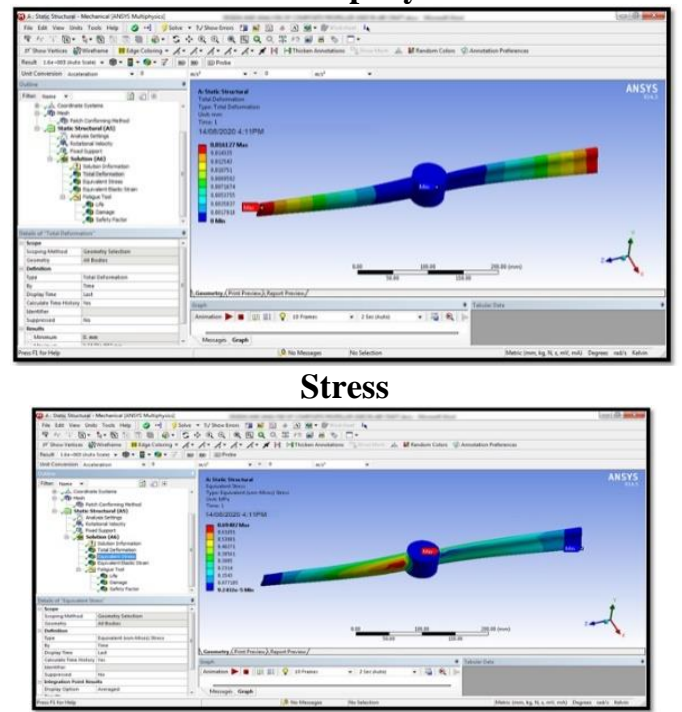

Strain

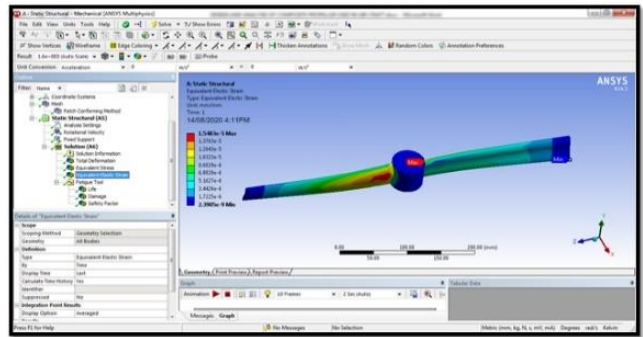




\section{Material- carbon epoxy}

Deformation

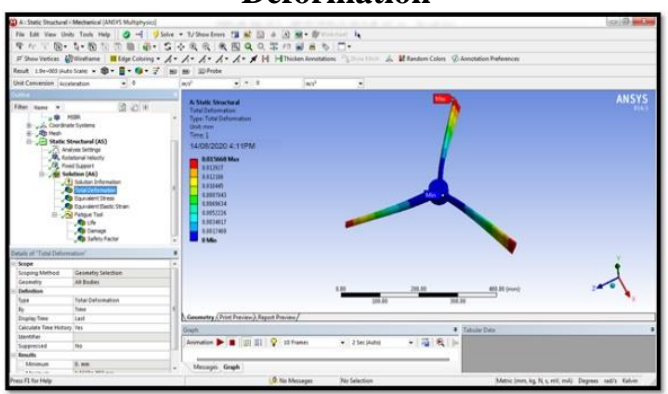

\section{Stress}

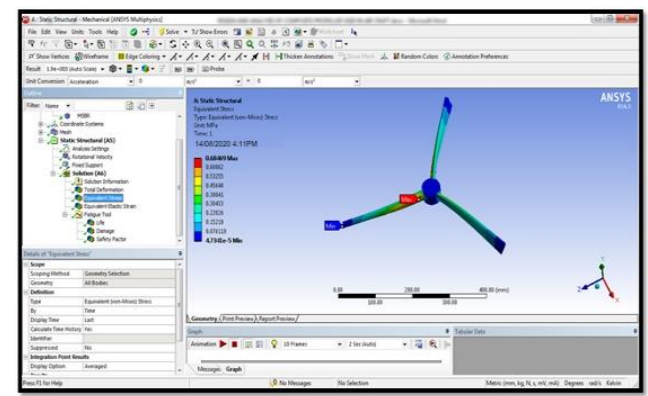

Strain

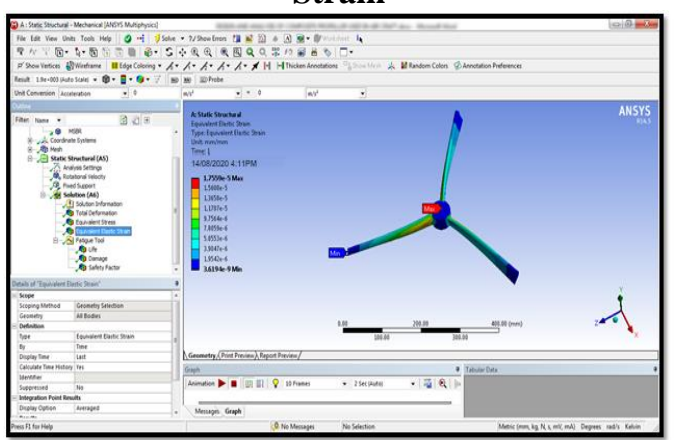

Material- carbon epoxy

Deformation

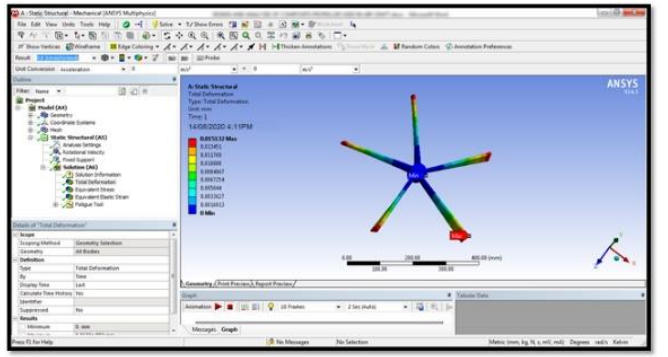

\section{Stress}

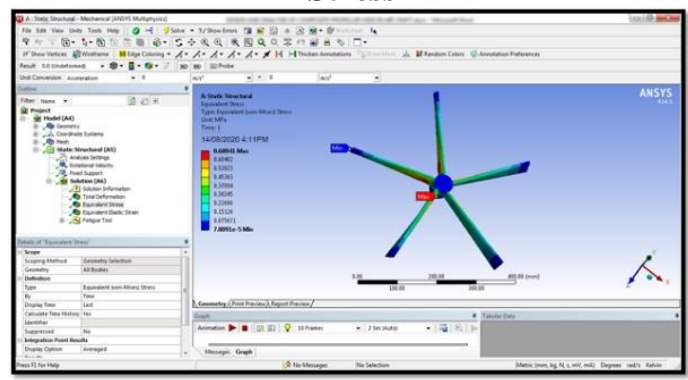

Strain

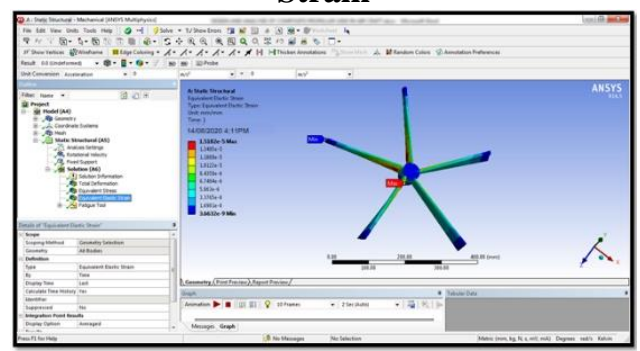

At time 10sec

Deformation

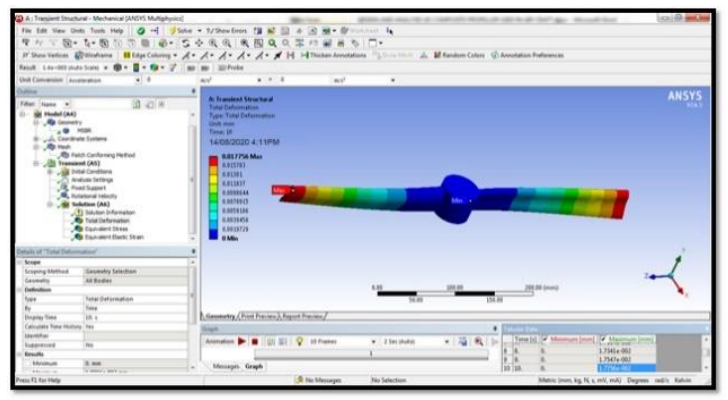

Stress

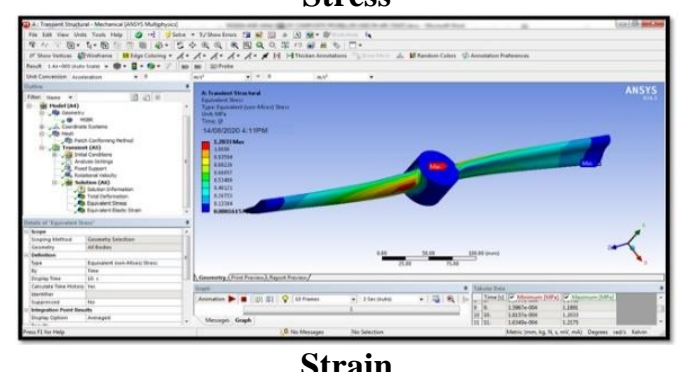

Strain

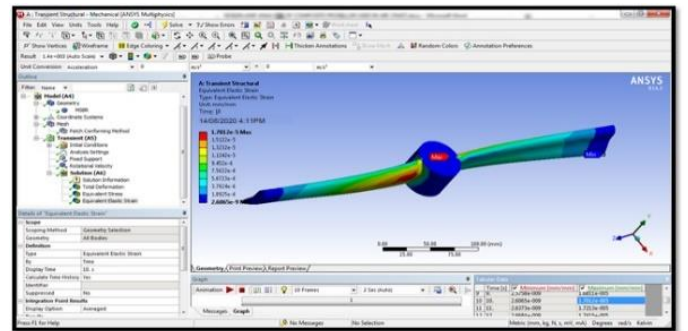

At time 20sec

Deformation

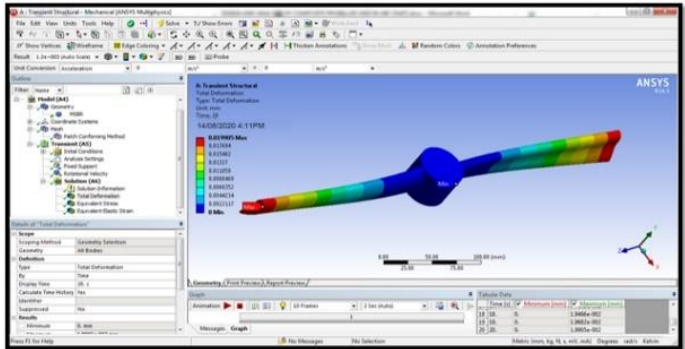

Stress

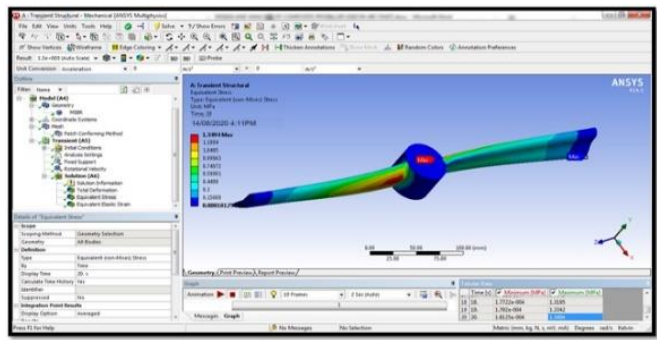




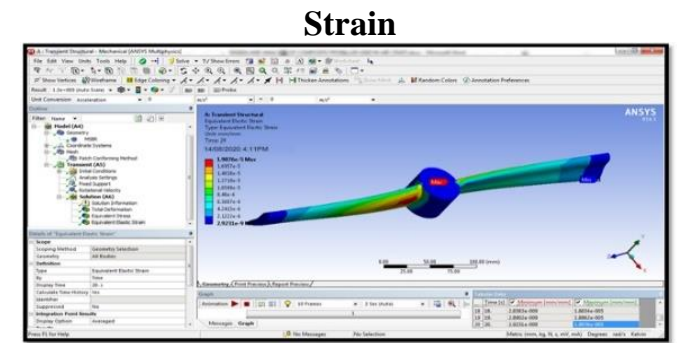

Material- aluminum alloy At time 10sec

Deformation

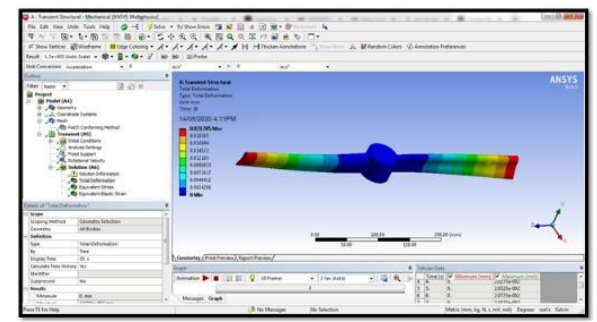

Stress

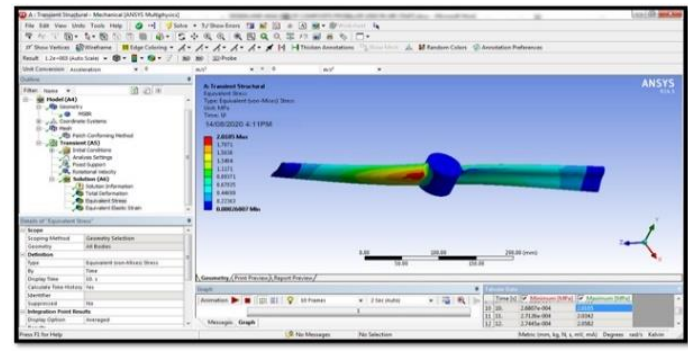

Strain

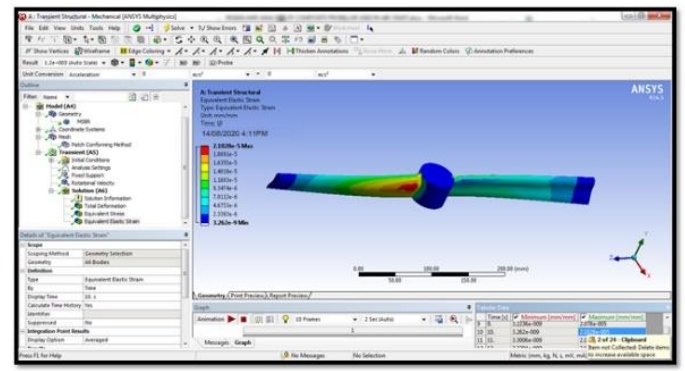

At time 20sec

Deformation

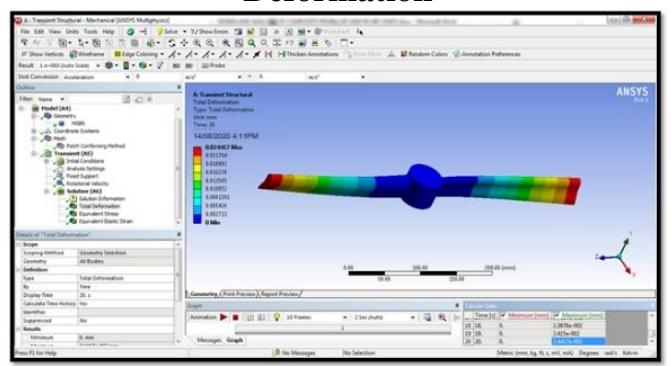

Stress

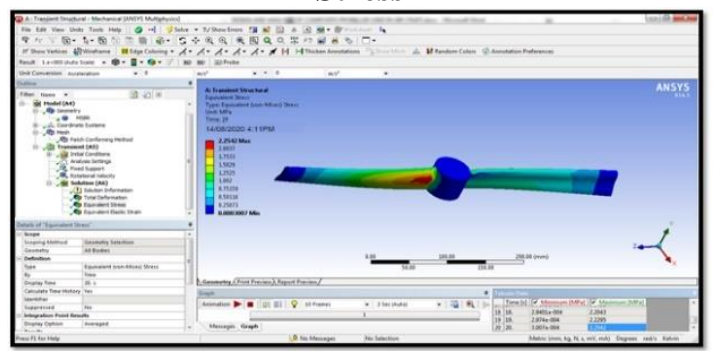

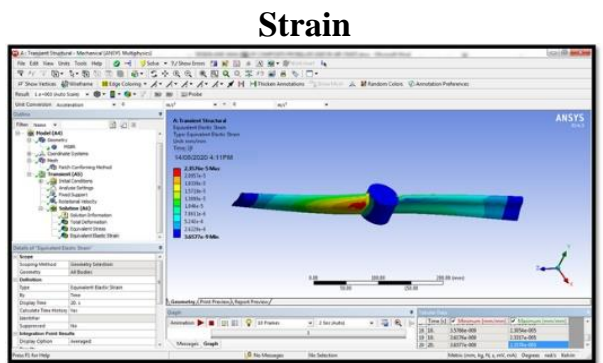

Static analysis table

\begin{tabular}{|c|c|c|c|c|c|}
\hline Models & Materials & $\begin{array}{c}\text { Deformation } \\
(\mathrm{mm})\end{array}$ & $\begin{array}{l}\text { Stress } \\
\text { (MPa) }\end{array}$ & Strain & $\begin{array}{l}\text { Safety } \\
\text { factor }\end{array}$ \\
\hline \multirow[t]{3}{*}{2 blades } & Carbon epoxy & 0.01627 & 0.69402 & $1.5483 \mathrm{e}-5$ & 1.242 \\
\hline & e-glass epoxy & 0.015777 & 1.0668 & $1.5082 \mathrm{e}-5$ & 0.80803 \\
\hline & Aluminum alloy & 0.01937 & 1.7827 & $1.8645 \mathrm{e}-5$ & 0.48354 \\
\hline \multirow[t]{3}{*}{3 blades } & Carbon epoxy & 0.015668 & 0.68469 & $1.7559 \mathrm{e}-5$ & 1.259 \\
\hline & e-glass epoxy & 0.015336 & 1.0533 & $1.6663 \mathrm{e}-5$ & 0.81836 \\
\hline & Aluminum alloy & 0.018814 & 1.7577 & $2.1404 \mathrm{e}-5$ & 0.4904 \\
\hline \multirow[t]{3}{*}{5 blades } & Carbon epoxy & 0.015132 & 0.68041 & $1.518 \mathrm{e}-5$ & 1.2669 \\
\hline & E-glass epoxy & 0.014832 & 1.0429 & $1.4744 \mathrm{e}-5$ & 0.82657 \\
\hline & Aluminum alloy & 0.018156 & 1.7501 & $1.8307 \mathrm{e}-5$ & 0.49255 \\
\hline
\end{tabular}

\begin{tabular}{|c|c|c|c|c|c|}
\hline Models & Materials & $\begin{array}{l}\text { Time } \\
\text { (sec) }\end{array}$ & $\begin{array}{c}\text { Deformation } \\
(\mathbf{m m})\end{array}$ & $\begin{array}{l}\text { Stress } \\
\text { (MPa) }\end{array}$ & Strain \\
\hline \multirow[t]{6}{*}{2 blades } & \multirow[t]{2}{*}{ Carbon epoxy } & 10 & 0.021785 & 2.0105 & $2.1028 \mathrm{e}-5$ \\
\hline & & 20 & 0.024417 & 2.2542 & $2.3576 \mathrm{e}-5$ \\
\hline & \multirow[t]{2}{*}{ e-glass epoxy } & 10 & 0.017756 & 1.2033 & $1.7012 \mathrm{e}-5$ \\
\hline & & 20 & 0.019905 & 1.3494 & $1.9076 \mathrm{e}-5$ \\
\hline & \multirow{2}{*}{$\begin{array}{c}\text { Aluminum } \\
\text { alloy }\end{array}$} & 10 & 0.018148 & 0.7828 & $1.7464 \mathrm{e}-5$ \\
\hline & & 20 & 0.020345 & 0.87722 & $1.9884 \mathrm{e}-5$ \\
\hline \multirow[t]{6}{*}{3 blades } & \multirow[t]{2}{*}{ Carbon epoxy } & 10 & 0.017632 & 0.77215 & $1.9823 \mathrm{e}-5$ \\
\hline & & 20 & 0.019767 & 0.86585 & $2.2232 \mathrm{e}-5$ \\
\hline & \multirow[t]{2}{*}{ e-glass epoxy } & 10 & 0.01726 & 1.879 & $1.8512 \mathrm{e}-5$ \\
\hline & & 20 & 0.019349 & 1.332 & $2.1097 \mathrm{e}-5$ \\
\hline & \multirow{2}{*}{$\begin{array}{c}\text { Aluminum } \\
\text { alloy }\end{array}$} & 10 & 0.02116 & 1.9819 & $2.4166 \mathrm{e}-5$ \\
\hline & & 20 & 0.02372 & 2.2224 & $2.7102 \mathrm{e}-5$ \\
\hline \multirow[t]{6}{*}{5 blades } & \multirow[t]{2}{*}{ Carbon epoxy } & 10 & 0.01827 & 0.7707 & $1.7192 \mathrm{e}-5$ \\
\hline & & 20 & 0.020482 & 0.86423 & $1.9279 \mathrm{e}-5$ \\
\hline & \multirow[t]{2}{*}{ e-glass epoxy } & 10 & 0.017916 & 1.1837 & $1.6713 \mathrm{e}-5$ \\
\hline & & 20 & 0.020086 & 1.3273 & $1.8742 \mathrm{e}-5$ \\
\hline & \multirow{2}{*}{$\begin{array}{l}\text { Aluminum } \\
\text { alloy }\end{array}$} & 10 & 0.021905 & 1.982 & $2.0728 \mathrm{e}-5$ \\
\hline & & 20 & 0.024555 & 2.2225 & $2.3243 \mathrm{e}-5$ \\
\hline
\end{tabular}

\section{CONCLUSION}

The present work is directed towards the study of composite aircraft propeller working and its terminology, simulation and flow simulation of composite aircraft propeller has been performed. To analyze the composite aircraft propeller in ANSYS software.

Static and dynamic analysis is to determined the deformation, stress and strain of the composite aircraft propeller blade. Fatigue analysis to estimate the life of the component.

The optimized the propeller blades varying the no of blades $2,3 \& 5$ blades and also optimized the material E-glass Epoxy, Aluminum Alloy and Carbon Epoxy. 3D modeling done in CATIA parametric software.

By observing the static analysis results the less stress has 5 blades propeller compare with 2 blades and 3blades and comparison between materials the less stress has carbon epoxy material than e-glass epoxy and aluminum alloy.

By observing the fatigue analysis results the more safety factor has 5 blades propeller compare with 2 blades and 
3blades and comparison between materials the less safety factor has carbon epoxy material than e-glass epoxy and aluminum alloy.

By observing the dynamic analysis results the less stress has 5 blades propeller compare with 2 blades and 3blades and comparison between materials the less stress has carbon epoxy material than e-glass epoxy and aluminum alloy.

So it can be concluded the aircraft propeller with 5 blades and carbon epoxy material is the better.

\section{REFERENCES}

[1] Das. H. N and Kapuria, S., "On the use of bend-twist coupling in full-scale composite marine propellers for improving hydrodynamic performance", Journal of Fluids and Structures, Vol. 61, 2016, pp: 132-153.

[2] Rao, Y. S., and Reddy, B. S., "Harmonic Analysis of Composite Propeller for Marine Applications", International Journal of Research \& Technology (IJERT), Vol.1 Nov-2012 pp: 257-260

[3] Khan, M. A., Uddin, K. S.,and Ahmed, B., "Design and Dynamic Analysis on Composite Propeller of Ship Using FEA", International Journal of Research \& Technology(IJERT),Vol.2, January-2013, pp: 310-315

[4] Ganesh,V., Pradeep, K., and Srinvasulu, K., "Modelling and Analysis of Propeller Blade for its Strength" International Journal of Research \& Technology(IJERT),Vol.3, February2014, pp: 291300

[5] Yeo, K. B., Choong, W. H., and Hau, W. Y., "Prediction of Propeller Blade Stress Distribution Through FEA", Journal of Applied Sciences,Vol.14,2014, pp.3046-3054.

[6] Barros,E. A. De., and Dantas, J.L.D., "Effect of Propeller Duct on AUV Maneuverability”, Ocean Engineering, Vol.42, 2012 pp:6170

[7] Wei, Y. S., Wang, Y., Chang, S., and Fu, J., "Numerical Prediction of Propeller Excited Acoustic Response of Submarine Structure Based on CFD, FEM and BEM", Journal of Hydrodynamics, Vol. 24 pp: 207-216

[8] Paik, B. G., Kim, G. D., Kim, K.Y., Seol, H.S., Hyun B. S.,Lee, S. G., Jung Y. R., "Investigation on the Performance Characteristics of the Flexible Propellers", Ocean Engineering, Vol.73, 2013, pp: 139-148. 